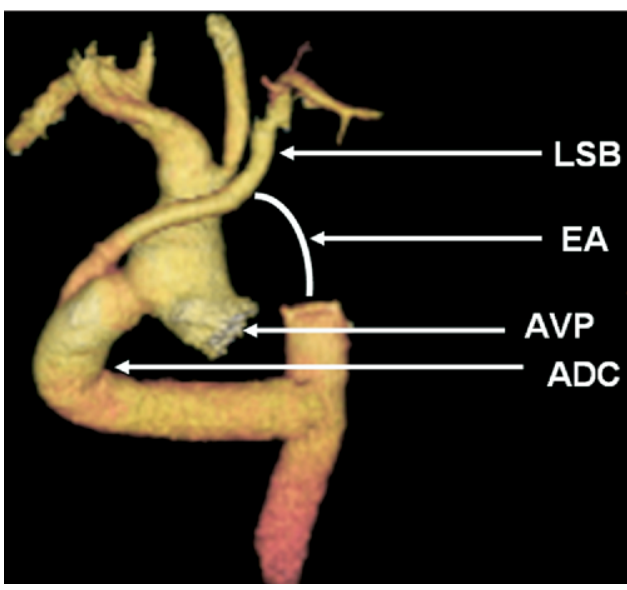

Figure 2. Reconstructed CT angiogram at 1 year. There is an ascending-descending aortic conduit (ADC) from the right side of the ascending aorta to the lower descending aorta. A side branch of the graft has been used to bypass (LSB) the excluded left subclavian artery. The aortic valve prosthesis (AVP) is shown. The aorta in the vicinity of the fistula is excluded (EA) from the aortic arch between the left common carotid and subclavian arteries and the mid-descending aorta.
We followed standard principles of fistula management, diverting the aorta away from the site of the presumed fistula and using visceral decompression to allow healing. ${ }^{4}$

AEF is a catastrophic complication of endovascular repair with limited therapeutic options. Definitive surgical treatment can lead to a successful outcome. ${ }^{5}$

\section{References}

1. Eggebrecht H, Baumgart D, Radecke K, von Birgelen C, Treichel U, Erbel R, et al. Aortoesophageal fistula secondary to stent-graft repair of the thoracic aorta. $J$ Endovasc Ther. 2004;11:161-7.

2. Hance KA, Hsu L, Eskew T, Hermreck AS. Secondary aortoesophageal fistula after endoluminal exclusion because of thoracic aortic transection. J Vasc Surg. 2003;37:886-8.

3. Knyshov GV, Sitar LL, Glagola MD, Atamanyuk MY. Aortic aneurysms at the site of the repair of coarctation of the aorta: a review of 48 patients. Ann Thorac Surg. 1996;61:935-9.

4. von Segesser LK, Tkebuchava T, Niederhauser U, Kunzil A, Lachat M Turina MI, et al. Aortobronchial and aortoesophageal fistulae as risk factors in surgery of descending thoracic aortic aneurysms. Eur J Cardiothorac Surg. 1997;12:195-201.

5. Czerny M, Zimpfer D, Fleck T, Mueller MR, Gottardi R, Cejna M, et al. Successful treatment of an aortoesophageal fistula after emergency endovascular thoracic aortic stent-graft placement. Ann Thorac Surg. 2005;80:1117-20

\title{
Occlusion of the left coronary ostium by an aortic valve leaflet
}

\author{
Shafi Mussa, MA, MRCS, ${ }^{a}$ Paul Miller, MBChB, DCH, FRCP, ${ }^{b}$ David J. Barron, MD, FRCP, FRCS, and
}

William J. Brawn, FRCS, FRACS, ${ }^{\text {a }}$ Birmingham, United Kingdom

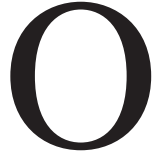

cclusion of the left coronary ostium by an aortic valve leaflet is a rare but well-described variant of aortic valve morphology. We report this finding in a neonate with a number of cardiac abnormalities, substantiating the theory that it is a congenital abnormality of aortic valve development.

From the Departments of Cardiothoracic Surgery and Pediatric Cardiol-

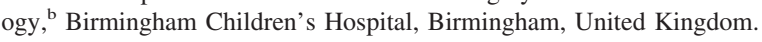

Received for publication July 25, 2007; accepted for publication Aug 7, 2007.

Address for reprints: William J. Brawn, FRCS, FRACS, Consultant Cardiothoracic Surgeon, Department of Cardiothoracic Surgery, Birmingham Children's Hospital, Steelhouse Lane, Birmingham B4 6NH, United Kingdom (E-mail: william.brawn@ bch.nhs.uk).

J Thorac Cardiovasc Surg 2007;134:1586-7

$0022-5223 / \$ 32.00$

Copyright $\odot 2007$ by The American Association for Thoracic Surgery doi:10.1016/j.jtcvs.2007.08.017

\section{Clinical Summary}

A 3-day-old boy who weighed $2.7 \mathrm{~kg}$ presented with poor feeding and lethargy after an uneventful normal vaginal delivery at term. Examination revealed tachypnea, poor peripheral pulses, and a systolic murmur. An echocardiogram revealed normal atrial arrangement, atrial septal defect with bidirectional flow, muscular outlet ventricular septal defect, subaortic stenosis (left ventricular outflow tract diameter of $4 \mathrm{~mm}$ ), dysplastic stenotic aortic valve with a maximum root diameter of $4.8 \mathrm{~mm}$ (Figure 1), type A interrupted aortic arch, moderate-sized ductus arteriosus, and normal-volume left ventricle with impaired systolic function. After stabilization with prostaglandin E2 $(7.5 \mathrm{ng} / \mathrm{kg} / \mathrm{min})$ and dobutamine $(5 \mu \mathrm{g} / \mathrm{kg} / \mathrm{min})$, surgery was undertaken at 9 days.

Operative findings included a bicuspid aortic valve with the large leftward leaflet fused to the aortic wall over the left coronary sinus. Sharp dissection at the sinotubular junction released the leaflet and de-roofed the sinus, revealing 2 distinct left coronary ostia. The remaining surgery comprised aortic arch repair with formation of a Damus-Kaye-Stansel anastomosis, formation of a double-outlet left ventricle by enlarging the ventricular septal defect, and implantation of a bovine pericardial patch committing the aorta and main pulmonary artery to the left ventricle. An 

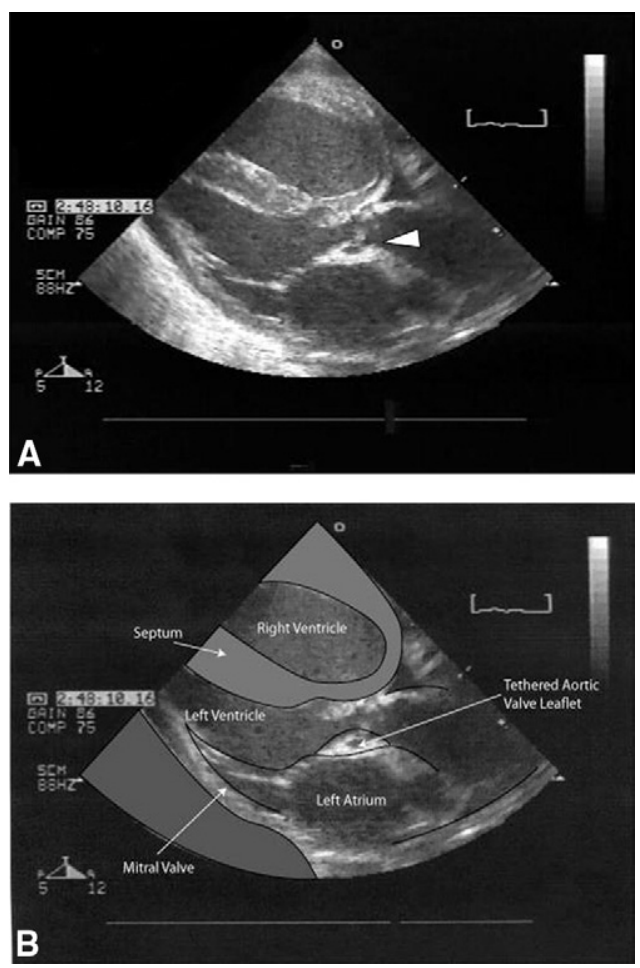

Figure 1. A, Still of a long-axis transthoracic echocardiogram depicting the dysplastic aortic valve with the leftward leaflet overlying the sinus of Valsalva subtending the left coronary artery. The "free margin" of the leaflet is adherent to the aortic wall at the sinotubular junction (white arrowhead). B, Still of the above long-axis echocardiogram with superimposed graphics to clearly delineate the cardiac chambers and the tethered aortic valve leaflet.

11-mm aortic homograft was used to create a right ventricularto-pulmonary artery conduit.

The child was returned to the intensive care unit in sinus rhythm and hemodynamically stable with the chest electively left open. An echocardiogram demonstrated good biventricular function and neoaortic flow with no regurgitation. An electrocardiogram demonstrated no ischemia. Subsequent recovery was satisfactory with chest closure on the fourth postoperative day and discharge from intensive care on the twelfth postoperative day.

During follow-up, the child has made excellent progress, gaining weight (9.6 kg at age 13 months), demonstrating resting saturations of $99 \%$ in air, and requiring no cardiac medication. Investigation at 24 months revealed good biventricular function, trivial aortic regurgitation, and an unobstructed left ventricular outflow tract. The left pulmonary artery appeared mildly compressed by the Damus connection, with no hemodynamic consequence.

\section{Discussion}

Occlusion of coronary ostia by an aortic valve leaflet is a rare but well-described anomaly. Previous cases in the literature have been described in adolescents or adults with symptoms suggestive of aortic stenosis. ${ }^{1,2}$ Of those who have presented with this condition in childhood, the youngest was aged 4 years. This is the first report describing this finding in a neonate.

The abnormal valvar morphology can be explained by the embryology of valve formation. The atrioventricular and ventriculoarterial valves are formed from endocardial cushions. Those that develop within the outflow tract of the primitive heart tube form the ventriculoarterial valves. There are 4 endocardial cushions in this region: 2 major cushions (septal and parietal) that spiral round each other in the outflow tract and 2 smaller intercalated cushions (aortic and pulmonary) that grow opposite each other (anteriorly and posteriorly respectively) in the outflow tract. Cavitation in the fused distal parts of all 4 cushions leaves the central luminal part of each cushion to form the arterial valvar leaflets, with the peripheral part arterializing to form the wall of the supporting valvar sinuses. ${ }^{3}$ The coronary arteries develop from primitive epicardial tissue and grow proximally toward the aortic sinuses. ${ }^{4}$ The proximal outflow tract remains encased by a cuff of primitive myocardial tissue, which the developing coronary arteries pierce before breaching the sinuses to reach the primitive aortic lumen, explaining why the proximal coronary arteries are not always morphologically abnormal in the context of variations in aortic valve morphology.

Other authors have suggested that this abnormality may occur secondary to an infective process. ${ }^{5}$ However, none of the patients with this anomaly were described to have a history of an infective process involving the myocardium, valves, or aorta. ${ }^{1}$ The theory that this is a developmental abnormality of the aortic valve is strongly supported by the combination of the above findings in a neonate and the known embryology of the aortic valve. Fusion of the free margin of the valve leaflet to the aortic wall at the sinotubular junction most likely represents failure of appropriate cavitation of the endocardial cushion tissue in the distal left ventricular outflow tract. Notably, the dysmorphic valve was one of several developmental anomalies of the left ventricular outflow tract. Had the dysmorphic valve been an isolated anomaly, the child may well have presented with symptoms of this abnormality later in life.

\section{References}

1. Kalimi R, Palazzo RS, Graver LM. Occlusion of left coronary artery ostium by an aortic valve cusp. Ann Thorac Surg. 2000;69:637-9.

2. Mutsuga M, Tamaki S, Yokoyama Y, et al. Acute occlusion of left coronary ostium associated with congenital quadricuspid aortic valve. Ann Thorac Surg. 2005;79:1760-1.

3. Anderson RH, Webb S, Brown NA, Lamers W, Moorman A. Development of the heart: (3) formation of the ventricular outflow tracts, arterial valves, and intrapericardial arterial trunks. Heart. 2003;89: $1110-8$.

4. Wada AM, Willet SG, Bader D. Coronary vessel development: a unique form of vasculogenesis. Arterioscler Thromb Vasc Biol. 2003;23:2138-45.

5. Waxman MB, Kong Y, Behar VS, Sabiston DC Jr, Morris JJ Jr. Fusion of the left aortic cusp to the aortic wall with occlusion of the left coronary ostium, and aortic stenosis and insufficiency. Circulation. 1970;41:849-57. 